\title{
MicroRNA-431 accelerates muscle regeneration and ameliorates muscular dystrophy by targeting Pax7 in mice
}

Rimao $\mathrm{Wu}^{1, \star}$, Hu Li ${ }^{1}{ }^{1 \star}$, Lili Zhai ${ }^{1}$, Xiaoting Zou${ }^{1}$, Jiao Meng ${ }^{1}$, Ran Zhong ${ }^{1}$, Changyin $\mathrm{Li}^{1}$, Haixia Wang ${ }^{2}$, Yong Zhang ${ }^{1} \&$ Dahai Zhu ${ }^{1}$

Skeletal muscle stem cells, called satellite cells, are a quiescent heterogeneous population. Their heterogeneity is influenced by Pax7, a well-defined transcriptional regulator of satellite cell functions that defines two subpopulations: $\mathrm{Pax} 7^{\mathrm{Hi}}$ and $\mathrm{Pax} 7^{\mathrm{LO}}$. However, the mechanisms by which these subpopulations are established and maintained during myogenesis are not completely understood. Here we show that miR-431, which is predominantly expressed in the skeletal muscle, mediates satellite cell heterogeneity by fine-tuning Pax7 levels during muscle development and regeneration. In miR-431 transgenic mice, the Pax $7^{\text {Lo }}$ subpopulation is enriched, enhances myogenic differentiation and accelerates muscle regeneration. Notably, miR-431 attenuates the muscular dystrophic phenotype in $m d x$ mice and may be a potential therapeutic target in muscular diseases. miR- 431 transgenic mice are a unique genetic model for investigating the cellular features and biological functions of Pax $7^{\text {Lo }}$ satellite cells during muscle development and regeneration.

\footnotetext{
${ }^{1}$ The State Key Laboratory of Medical Molecular Biology, Institute of Basic Medical Sciences, Chinese Academy of Medical Sciences and School of Basic Medicine, Peking Union Medical College, 5 Dong Dan San Tiao, Beijing 100005, China. ${ }^{2}$ Gladstone Institute of Cardiovascular Disease, Roddenberry Center for Stem Cell Biology and Medicine, 1650 Owens Street, San Francisco, California 94158, USA. * These authors contributed equally to this work. Correspondence and requests for materials should be addressed to Y.Z. (email: dr_zhangyong@126.com) or to D.Z. (email: dhzhu@pumc.edu.cn).
} 
A dult skeletal muscle has a remarkable regenerative capacity that is attributable to satellite cells (SCs), which express the paired-box transcriptional factor Pax7 (refs 1-4). In resting muscle, SCs are mostly quiescent; however, in response to stress or injury, they become activated and proliferated and either undergo differentiation or self-renewal to replenish the quiescent cell pool $^{5-8}$. During regeneration, skeletal muscle must strike a delicate balance between differentiation and self-renewal to maintain SC homeostasis ${ }^{9}$. This process is tightly regulated by extrinsic cues, namely by various factors in the stem-cell niche and by intrinsic transcriptional regulators, including Pax7, Myf5 and MyoD ${ }^{4,6,10-12}$. Pax7 contributes to SC activation, proliferation, self-renewal and differentiation by regulating expression of its target genes, such as Myf5 and MyoD ${ }^{13,14}$.

Pax7 is critical for the development and regeneration of skeletal muscles. In $\operatorname{Pax} 7$ knockout mice, the SC lineage is progressively lost through defective proliferation and self-renewal and precocious differentiation ${ }^{1,4,10,15}$. Pax7 also helps to direct and maintain the lineage specification of SCs, which in the absence of Pax7 and Pax3 differentiate into cartilage and other nonmuscle cell types ${ }^{16}$. Importantly, $\operatorname{Pax} 7^{+1+}$ cells are essential for adult skeletal muscle regeneration after skeletal muscle injury ${ }^{17}$.

More intriguingly, SCs are highly heterogeneous ${ }^{18,19}$, and recent studies have shown that different levels of Pax7 expression produce two subpopulations of $\mathrm{SCs}-\mathrm{Pax} 7^{\mathrm{Hi}}$ and $\mathrm{Pax} 7^{\mathrm{Lo}}$ - that have distinct biological features in mice ${ }^{20}$. Pax $7^{\mathrm{Lo}}$ cells are primed more for myogenic differentiation and less for self-renewal and higher metabolic status than $\mathrm{Pax}^{\mathrm{Hi}}$ cells. It is unclear which signals establish and maintain SC heterogeneity. Precise control of Pax7 levels is critical for its function in mediating SC heterogeneity ${ }^{20}$. During development and adult skeletal muscle regeneration, regulation of $\operatorname{Pax} 7$ expression is tightly correlated with SC function. Pax 7 is expressed abundantly in quiescent SCs but at much lower levels in activated SCs. Furthermore, $P a x 7$ downregulation is required for myogenic differentiation $^{21}$. However, the mechanism that governs Pax7 expression in SCs during muscle development and regeneration is unclear. A better understanding of this mechanism might help to reveal how $\mathrm{Pax} 7^{\mathrm{Hi}}$ and $\mathrm{Pax} 7^{\mathrm{Lo}}$ subpopulations are established and maintained.

MicroRNAs (miRNAs) help to regulate many cellular processes, including cell-fate determination, proliferation, differentiation and apoptosis, by refining gene expression at the transcriptional or post-transcriptional level ${ }^{22-26}$. Particularly, knocking out Dicer (an RNase III endonuclease responsible for miRNA maturation) in mouse skeletal muscle with MyoD-Cre or Pax7-Cre showed that many miRNAs are required for muscle development and SC functions ${ }^{27,28}$. For example, miR-1 and miR-133 are induced during skeletal muscle differentiation and are the key regulators of myoblast proliferation and differentiation ${ }^{29}$. miR-1 and miR-206 regulate SC differentiation by repressing $\operatorname{Pax} 7$ (ref. 30). miR-27a, which is expressed in differentiating skeletal muscle of the embryonic myotome and is activated in SCs of adult muscles, promotes SC differentiation by targeting Pax3 (ref. 31). miR-489, which is highly expressed in quiescent SCs and is quickly downregulated during SC activation, helps to maintain the quiescent state of adult stem-cell populations by targeting $D e k^{27}$. When miRNA expression in skeletal muscle is dysregulated, various skeletal muscle disorders ensue, including skeletal muscle hypertrophy and muscular dystrophy ${ }^{32-34}$.

Since Pax7 levels affect the heterogeneity of SCs and define two subpopulations, $\operatorname{Pax} 7^{\mathrm{Hi}}$ and $\operatorname{Pax} 7^{\mathrm{Lo}}$, and miRNAs help to finetune post-translational gene expression, we hypothesized that miRNA helps to establish and maintain these subpopulations by precisely modulating Pax7 levels. Here we describe the identification and characterization of miR-431, which is predominantly expressed in skeletal muscle tissue and regulates myogenic differentiation. We find that miR-431 mediates satellite-cell heterogeneity during muscle development and regeneration by targeting Pax7.

\section{Results}

Skeletal muscle-expressed miR-431 directly targets Pax7. To identify miRNAs important for fine-tuning Pax7 levels, we searched for potential miRNA-binding sites in the $3^{\prime}$-untranslated repeat (UTR) of Pax7 mRNA with TargetScan and miRanda. miR-431 (Supplementary Fig. 1) has two such binding sites (Fig. 1a) and resides within the miRNA cluster opposite to the orientation of the retrotransposon-like 1 (Rtll) gene in the Dlk1-Dio3 region (Supplementary Fig. 2). miR-431 is predominantly expressed in mouse skeletal muscle (Fig. 1b). During the rapid growth that occurs during the first 3 weeks of postnatal myogenesis, miR-431 is highly expressed (Supplementary Fig. 3). During in vitro differentiation of isolated SCs, miR-431 expression increases gradually (Fig. 1c); in parallel, Pax7 expression decreases (Fig. 1d). Moreover, we examined expression of Pax7 and miR-431 in freshly isolated myoblasts from muscle in postnatal 3-week pups (SC in proliferating state) and 12-week adult mice (SC in quiescence). Pax7 expression was significantly lower in 3- than in 12-week-old myoblasts; conversely, miR-431 was expressed at significantly higher levels in isolated myoblasts from 3-week-old mice than that from 12-week-old mice (Supplementary Fig. 4). Together, the unique expression pattern of miR-431 and its binding sites at the $3^{\prime}$-UTR of $P a x 7$ mRNA suggests that miR-431 regulates myogenesis by targeting Pax7.

To directly validate $\operatorname{Pax} 7$ as a target of $\operatorname{miR}-431$, we used a luciferase reporter construct containing a partial sequence of the Pax7-3'-UTR encompassing two miR-431-binding sites. Co-transfection of HEK 293 cells with miR-431 and the wild-type (WT) $3^{\prime}$-UTR of $\operatorname{Pax} 7$ (w-UTR) repressed luciferase activity (Fig. 1e). This repression was abolished by co-transfection with miR-431 and reporters containing mutant forms of the miR-431-binding sites on Pax7 (m1utr or m2utr; Fig. 1e). In $\mathrm{C} 2 \mathrm{C} 12$ cells overexpressing miR431, endogenous $\operatorname{Pax} 7$ mRNA levels were markedly reduced (Fig. 1f), confirming that miR-431 directly targets Pax7.

miR-431 promotes myogenic differentiation by targeting Pax7. Decreased Pax7 expression is required to initiate myogenic differentiation $^{21}$. In C2C12 cells, as in SCs (Fig. 1c), miR-431 expression was upregulated during differentiation (Supplementary Fig. 5). Since miR-431 targets Pax7 and miR-431 expression correlates negatively with $P a x 7$ expression, miR-431 may regulate myogenic differentiation by modulating $\mathrm{Pax} 7$ expression. To investigate this possibility, we stably overexpressed miR-431 or miR-1 (positive control) ${ }^{29}$ in $\mathrm{C} 2 \mathrm{C} 12$ cells. After confirming the overexpression using real-time reverse-transcription PCR (RT-PCR) (Supplementary Fig. 6), we placed the cells in differentiation medium for 12 and $36 \mathrm{~h}$, respectively, and assayed the expression of two markers of myogenic differentiation: myogenin $(M y o G)$ and myosin heavy chain $(M H C)$. Myogenic differentiation was stimulated to a much greater extent in cells expressing miR-431 than in negative controls, as shown by the greater abundance of $\mathrm{MyoG}^{+}$(Fig. 2a) and $\mathrm{MHC}^{+}$cells (Fig. 2d) and by the higher levels of $M y o G$ mRNA (Fig. 2b) and protein (Fig. 2c) and MHC mRNA (Fig. 2e) and protein (Fig. 2f). miR-431 and miR-1 enhanced differentiation to a similar extent (Fig. $2 \mathrm{a}, \mathrm{d}$ ), revealing that miR-431 regulates myogenic cell differentiation. To determine whether miR-431 does so by targeting Pax7, we overexpressed Pax7 in C2C12 cells stably 
a

$$
\begin{aligned}
& \text { Pax7 3' UTR 5'...UCCUGCCCUCAGCCAGCAAGACA.. } \\
& \text { mmu-miR-431 3' ACGUACUGCCGGACGUUCUG } \\
& \text { Mutant (m1utr): CGAACGG }
\end{aligned}
$$
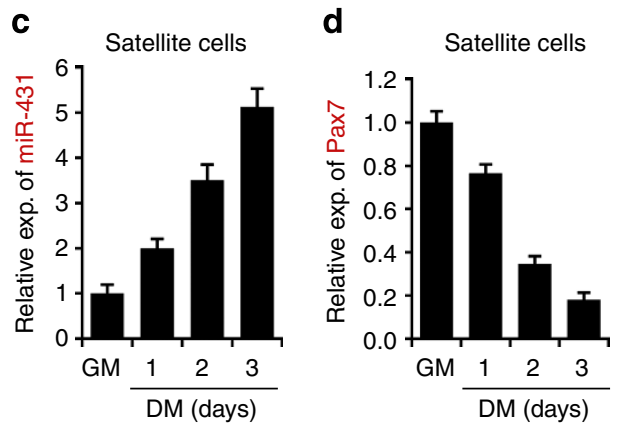

b
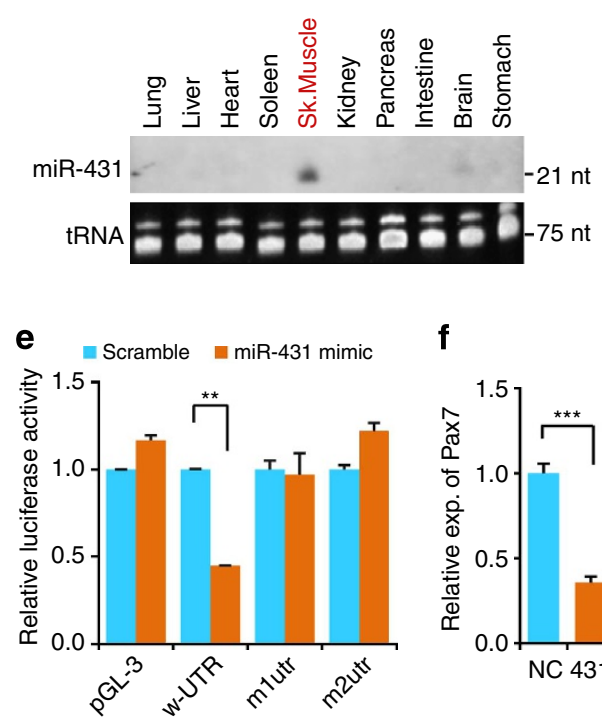

Figure 1 | miR-431 is predominantly expressed in the skeletal muscle and targets Pax7 in myogenic cells. (a) miR-431 target sequence alignment in the Pax7 3'-UTR predicted with TargetScan. Two predicted target sites of miR-431 in the 3'-UTR of mouse Pax7 are shown. The nucleotide coordinate of Pax7 was based on the mouse Refseq (NM_011039). mlutr and m2utr, mutated from the seed matches, are indicated. (b) Expression of miR-431 in tissues from 3-week-old mice was analysed using northern blot analysis. Total RNA ( $20 \mu \mathrm{g})$ was loaded to detect miR-431, and tRNA was used as a loading control. (c,d) Expression of miR-431 and Pax7 during satellite cell proliferation (growth medium; GM) and differentiation (differentiation medium; DM) was assayed using real-time RT-qPCR. U6 small nuclear RNA (snRNA) served as an internal control for miR-431 expression, and GAPDH as a control for Pax7 detection. exp, expression. (e) Effect of miR-431 transfection in HEK 293 cells, measured with luciferase assays. Empty pGL-3 vector was a negative control. w-UTR is a Pax7-3'-UTR, with miR-431-binding site inserted downstream of the luciferase gene in the pGL-3 control vector. m1utr and m2utr are mutant forms of the Pax7 3'-UTR. A Renilla luciferase plasmid was co-transfected with a firefly luciferase construct as a transfection control. The results are expressed as firefly luciferase activity relative to Renilla luciferase activity. Values are means \pm s.e.m. of three independent measurements. ${ }^{\star \star} P<0.01$. (f) miR-431 was overexpressed in $\mathrm{C} 2 \mathrm{C} 12$ cells with a lentiviral system. Cells stably expressing a scramble sequences served as negative controls (NC). Pax7 expression was determined using RT-qPCR. Error bars represent means \pm s.e.m. of three independent experiments. ${ }^{\star \star \star} P<0.001$. Two-tailed Student's $t$-test was used for all statistical testings.

expressing miR-431 (Supplementary Fig. 7). Pax7 overexpression abolished the differentiation induced by miR-431, as indicated by the reactivity (Fig. 2g,h) and expression (Fig. 2i) of MHC.

$\operatorname{Pax}^{\text {Lo }}$ SCs are enriched in miR-431 transgenic mice. To investigate how the miR-431-Pax7 axis regulates muscle development and regeneration in vivo, we generated two lines of miR-431 transgenic (TG) mice (Supplementary Fig. 8a). Real-time RT-PCR analysis showed 4-fold overexpression of miR-431 in the $\mathrm{H}$ line and 20-fold overexpression in the $\mathrm{O}$ line (Supplementary Fig. 8b). Similar to their WT littermates, neither line had histological or overt physiological abnormalities in skeletal muscle during development (Supplementary Fig. 8c-f). In skeletal muscle, expression of $\operatorname{Pax} 7$ mRNA was significantly lower in both TG mouse lines than in WT littermate controls (Fig. 3a,b). The reduced expression did not reflect fewer SCs, which were presented at similar numbers in Pax7-stained muscle sections of WT and TG mice (Fig. 3c).

Next, we generated Pax7-Cre::Rosa26-mTmG::miR-431 reporter mice and WT controls (Pax7-Cre::Rosa26-mTmG) and isolated green fluorescent protein (GFP)-positive SCs by fluorescence-activated cell sorting (FACS; Fig. 3d). Despite equal numbers of sorted cells in the two groups, $\operatorname{Pax} 7$ expression was remarkably lower in SCs of Pax7-Cre::Rosa26-mTmG::miR-431 mice (Fig. 3e).

Since miR-431 targeted Pax7 in SCs, and TG SCs expressed significantly less $P a x 7$, we suspected that SCs in miR-431 TG mice are enriched in the Pax $7^{\text {Lo }}$ subpopulation. To directly test this possibility, we examined the expression of endogenous miR-431 and Pax7 in sorted Pax $7^{\mathrm{Hi}}$ and Pax $7^{\mathrm{Lo}}$ SCs from skeletal muscle of Pax7-Cre::Rosa26-mTmG mice as described ${ }^{20}$ (Fig. 3f). The miR-431 levels were much lower in $\mathrm{Pax}^{\mathrm{Hi}}$ cells and much higher in the Pax7 ${ }^{\mathrm{Lo}}$ cells (Fig. 3g). Moreover, the Pax7 ${ }^{\mathrm{Lo}}$ subpopulation in sorted cells was increased in TG mice at the expense of decreased $\mathrm{Pax}^{\mathrm{Hi}}$ (Fig. 3h,i, Supplementary Fig. 9). In addition, overexpression of miR-431 shifted the overall profile of SC population towards Pax $7^{\text {Lo }}$ (Fig. 3j). Therefore, although there was a $5 \%$ increase in $\mathrm{Pax}^{\mathrm{Lo}}$ cells, we did observe the overall twofold Pax7 reduction in the entire population assessed with sensitive quantitative RT-PCR (qRT-PCR; Fig. 3e). In addition, SCs from TG mice expressed lower levels of Pax7 and stemnessrelated genes, including $\mathrm{C}-\mathrm{X}-\mathrm{C}$ chemokine receptor type 4 (CXCR4) and cluster of differentiation 34 (CD34), but highly expressed the myogenic differentiation gene $M y o G$ and the mitochondria genes, mitochondrial-specific polymerase $\gamma$ (catalytic PolG and accessory PolG2), and mitochondrial transcription factor A (Tfam; Fig. 3k), which are typical features of Pax7-nGFP ${ }^{\text {Lo }}$ cells. Thus, miR-431 TG mice are a potential model system for investigating the biological features of Pax $7^{\text {Lo }}$ cells in vivo.

miR-431-mediated Pax $7^{\text {Lo }}$ SCs are primed for differentiation. To characterize the function of Pax $7^{\text {Lo }}$ SCs in miR-431 TG mice, we first assessed their myogenic differentiation capability. Freshly isolated SCs from the hindlimb skeletal muscle of TG and WT mice were cultured in the growth medium for $48 \mathrm{~h}$ and were 
a

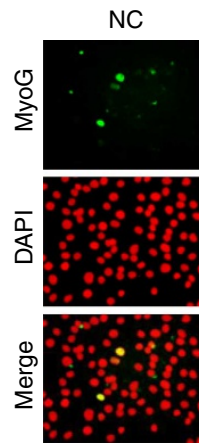

b

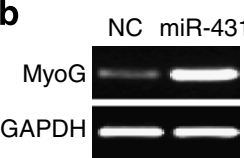

$\operatorname{miR}-431$
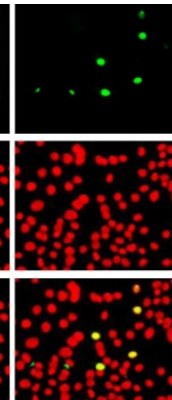

C

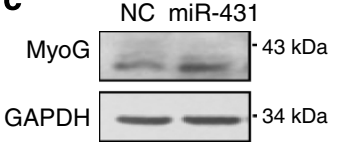

g
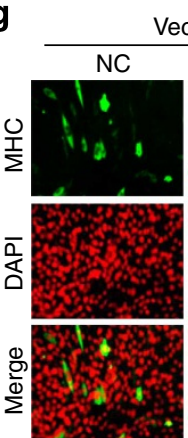

Vector miR-431

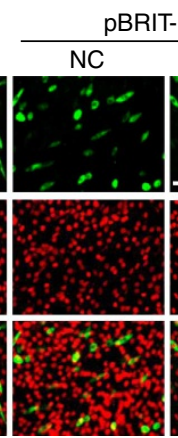

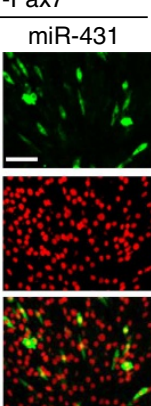

d
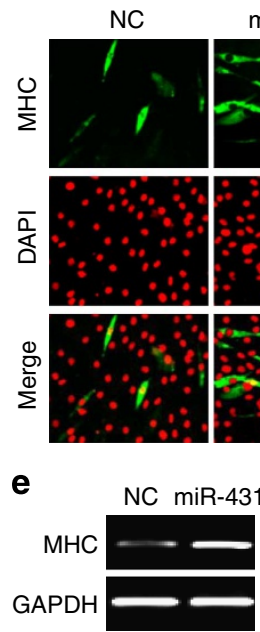

h

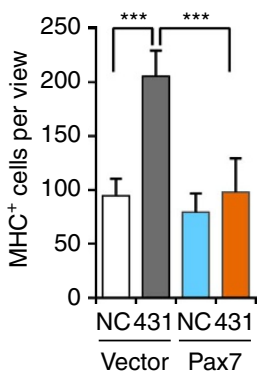

f
$\operatorname{miR}-431$
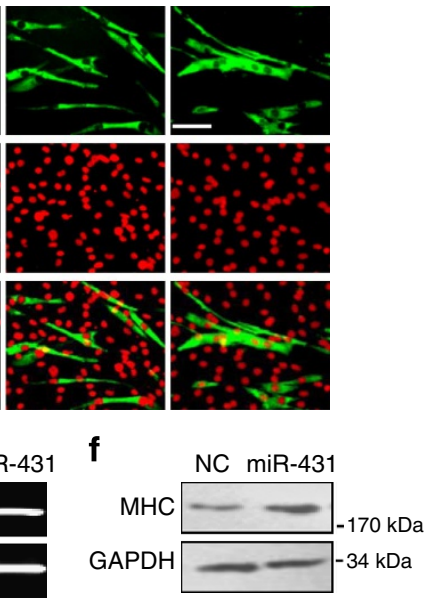

i

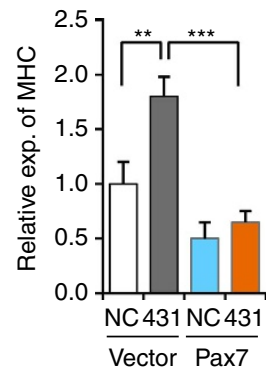

Figure 2 | miR-431 promotes myogenic differentiation by targeting Pax7. (a) The differentiation of C2C12 cells stably overexpressing miR-431 was examined by staining for MyoG after $12 \mathrm{~h}$ of culture in DM. Cells overexpressing miR-1 served as the positive control and cells with an empty vector as the NC. Scale bar, $50 \mu \mathrm{m}$. (b,c) MyoG expression in the $\mathrm{C} 2 \mathrm{C} 12$ cells described in a was analysed using semiquantitative RT-PCR (b) and western blot analysis (c). GAPDH was the loading control. (d)The differentiation of $\mathrm{C} 2 \mathrm{C} 12$ cells stably overexpressing miR-431 was examined by staining for $\mathrm{MHC}$ after $36 \mathrm{~h}$ of culture in DM. Cells overexpressing miR-1 served as the positive control and cells with an empty vector as the NC. Scale bar, $50 \mu \mathrm{m}$. (e,f) The expression of MHC in $\mathrm{C} 2 \mathrm{C} 12$ cells in $\mathbf{d}$ was analysed using semiquantitative RT-PCR (e) and western blot analysis (f). GAPDH was the loading control. (g) Pax7 was overexpressed in $\mathrm{C} 2 \mathrm{C} 12$ cells stably overexpressing miR-431 and NC cells. Differentiation of $\mathrm{C} 2 \mathrm{C} 12$ cells was examined by staining for $\mathrm{MHC}$ after $24 \mathrm{~h}$ of culture in DM. Scale bar, $50 \mu \mathrm{m}$. (h) $\mathrm{MHC}^{+}$cells were calculated based on staining described in panel $\mathbf{g}$. (i) $\mathrm{MHC}$ expression in the cells in $\mathbf{g}$ detected using real-time qRT-PCR. GAPDH was the internal control. Error bars represent means \pm s.e.m. of three independent experiments. ${ }^{\star \star} P<0.01,{ }^{\star \star \star} P<0.001$. Twotailed Student's t-test was used for all statistical testing.

immunostained with antibodies against $\mathrm{MyoD}$ and $\mathrm{MyoG}$ (Fig. 4a). MyoD ${ }^{+}$and $\mathrm{MyoG}^{+}$TG cells were significantly more abundant (Fig. 4b), indicating greater myogenic differentiation. Consistently, the differentiation of isolated primary myoblasts was also greater in the TG mice (Supplementary Fig. 10).

Next, we investigated the differentiation and self-renewal of SCs-which must be precisely balanced to maintain muscle tissue homeostasis during normal development and regeneration-in myofibre-associated SCs. In single fibres isolated from extensor digitorum longus (EDL) muscle and cultured ex vivo for $72 \mathrm{~h}$, immunostaining showed the typical clusters of SC progeny that are proliferating $\left(\mathrm{Pax}^{+} / \mathrm{MyoD}^{+}\right)$, differentiating $\left(\mathrm{Pax}^{-} / \mathrm{MyoD}^{+}\right)$ and self-renewing ( $\mathrm{Pax}^{+} / \mathrm{MyoD}^{-}$; Fig. $\left.4 \mathrm{c}\right)$. However, miR-431 TG myofibres had significantly more differentiating cells and significantly fewer self-renewing cells than WT controls (Fig. 4d), indicating precocious onset of differentiation in the TG cells. Together, our ex vivo and in vivo data convincingly suggest that miR-431 TG mice are enriched in Pax $7^{\mathrm{Lo}}$ SCs that are primed more for differentiation and less for self-renewal.

Muscle regeneration is accelerated in miR-431 TG mice. Since miR-431 targets Pax7 and promotes muscle cell differentiation in vitro, we next investigated how it regulates SC function during muscle regeneration. Muscle regeneration was induced by injecting cardiotoxin (CTX) into tibialis anterior (TA) muscle of WT and miR-431 TG mice of lines $\mathrm{O}$ and $\mathrm{H}$. Similar results were obtained in both TG lines; therefore, we present data from the $\mathrm{H}$ line.

During regeneration, miR-431 expression dropped immediately in response to injury after CTX injection (Supplementary Fig. 11), consistent with the greater downregulation of miR-431 in activated than in quiescent $\mathrm{SCs}^{27}$. Myogenic differentiation happens within 3 days post injury during muscle regeneration; we indeed observed increased expression of miR-431 at 3 days and it was remarkably elevated after the time point (Supplementary Fig. 11). This expression pattern suggests that miR-431 helps to mediate SC function during regeneration of damaged muscle. In support of this notion, at 7 days after injection, regenerating myofibres, characterized by centralized nuclei, were significantly larger in miR-431 TG mice than in WT controls (Fig. 5a,b).

Next, to evaluate the influence of miR-431 on SC activation, proliferation and differentiation during regeneration, we immunostained sections with antibodies against Pax7 and MyoD (Fig. 5c,f). Pax7 is expressed in quiescent and activated SCs, and MyoD is expressed in SCs that are activated during muscle 
a

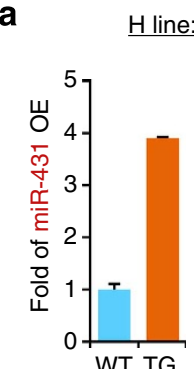

line: muscle

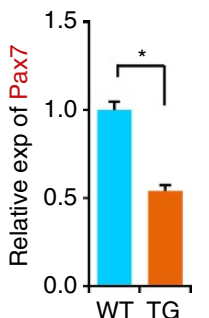

d Rosa-mTmG

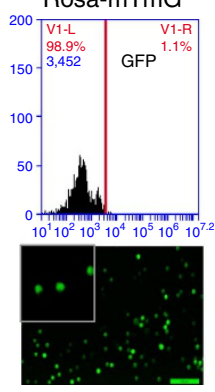

Pax7-Cre::mTmG

g

Sorted subpopulation of $\mathrm{Hi}$ and $\mathrm{Lo}$

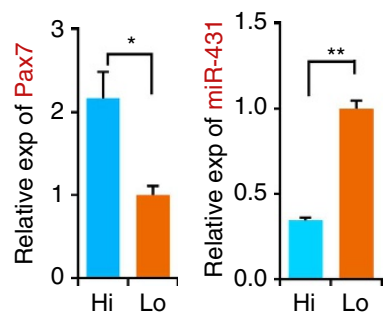

j

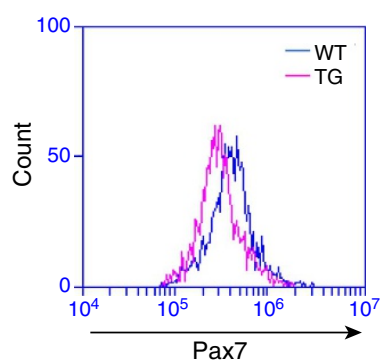

b
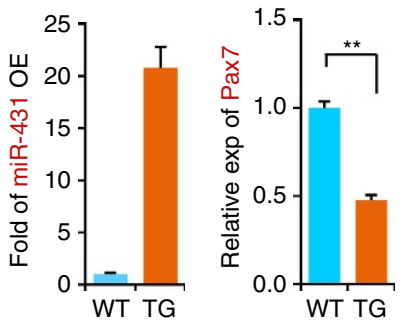

e

Sorted satellite cells
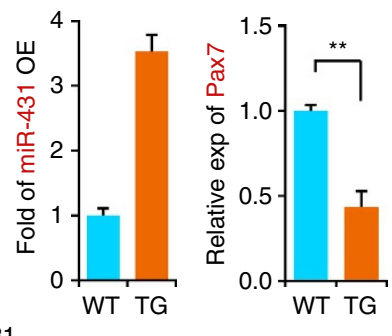

h
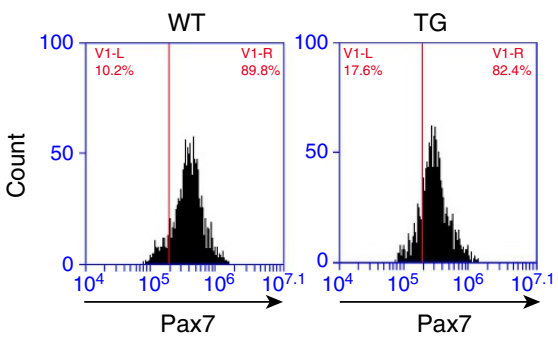

i

k

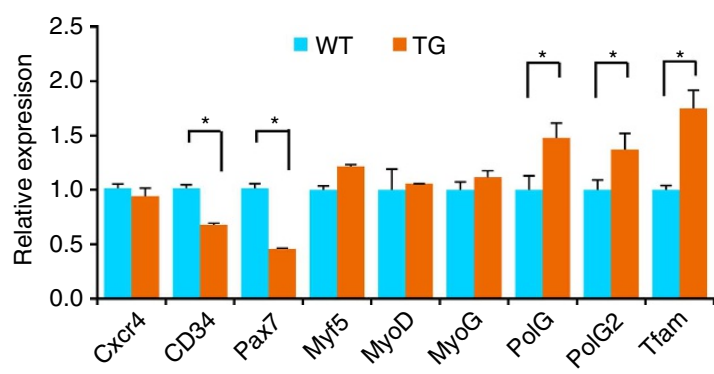

Figure 3 | Satellite cells in miR-431 TG mice have Pax $7^{\mathbf{L} 0}$ characteristics. miR-431 TG mice were generated in which transgene expression was driven by the $\beta$-actin promoter (pCAGGS). Two lines of the TG mice ( $\mathrm{H}$ and $\mathrm{O}$ ) were used. Values are mean \pm s.e.m. or one representative value from four to five pairs of WT and TG mice. ${ }^{\star} P<0.05,{ }^{\star \star} P<0.01$. NS, not significant. Two-tailed Student's $t$-test was used for all statistical testings. (a,b) miR-431 overexpression (OE) levels in the skeletal muscle of the $\mathrm{H}(\mathbf{a})$ and $\mathrm{O}(\mathbf{b})$ lines were examined using real-time RT-PCR with TaqMan probe. U6 snRNA was the internal control. Pax7 expression in the same samples was analysed using real-time RT-PCR and GAPDH was the internal control. (c) Number of satellite cells in cryosections of TA muscle, stained for Pax7, from miR-431 TG mice and WT controls. (d) Satellite cells were genetically labelled with GFP by crossing miR-431 TG mice with Pax7Cre::RosamTmG reporter mice. GFP ${ }^{+}$cells from the skeletal muscle of Pax7-Cre:::RosamTmG::miR-431 mice and Pax7-Cre::RosamTmG controls were sorted using FACS. (e) miR-431 OE in FACS-sorted satellite cells from d was determined using real-time RT-PCR. U6 snRNA was the internal control. Pax7 expression in the same samples was determined using real-time RT-PCR and GAPDH was the internal control. (f) Satellite cells sorted from the skeletal muscle of Pax7-Cre::RosamTmG mice were stained with Pax7, and the stained cells were sorted with FACS into Pax $7^{\mathrm{Hi}}$ and Pax $7^{\mathrm{Lo}}$ subpopulations. (g) Expression levels of miR-431 and Pax7 in the Pax $7^{\mathrm{Hi}}$ and Pax $7^{\mathrm{Lo}}$ satellite cells from $\mathbf{f}$ were analysed using real-time PCR. (h) Satellite cells were sorted by FACS to select CD31-CD45-Sca1-VCAM + from miR-431 TG and WT mice and stained with Pax7; the stained satellite cells were further sorted by FACS to calculate Pax $7^{\text {Lo }}$ subpopulations. (i) The percentage of the Pax $7^{\text {Lo }}$ subpopulation were calculated based on $\mathbf{h}, \mathbf{j}$. Overall profile of $\mathrm{Pax}^{+}$cells sorted in $\mathbf{h}, \mathbf{k}$. Expressions of the stemness-, differentiation- and mitochondria-related markers, determined using real-time RT-PCR in sorted satellite cells from miR-431 TG and WT mice.

regeneration ${ }^{10,35,36}$. At 1 day after CTX injection, $\mathrm{MyoD}^{+}$cells were more numerous in TG mice (Fig. $5 \mathrm{~d}$ ) and MyoD protein was more abundant in TG muscle (Fig. 5e). Thus, miR-431 promoted
SC activation early on during muscle regeneration. Moreover, at 3 days after injection, TG mice also had more Pax7 ${ }^{+}$and $\mathrm{MyoD}^{+}$ cells (Fig. 5f,g) and more Pax7 and MyoD proteins (Fig. 5h), 
a
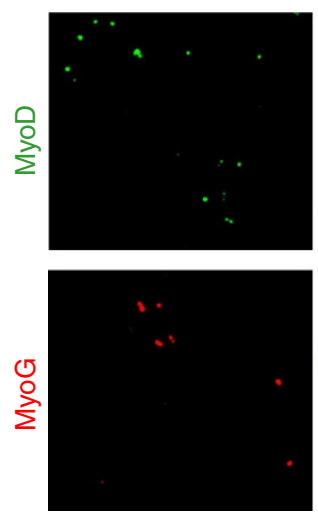

C

$\operatorname{Pax} 7$

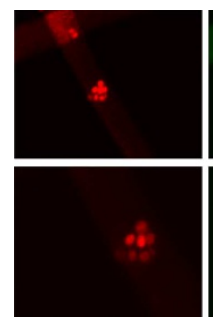

MyoD

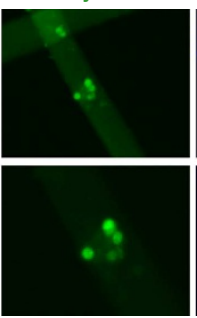

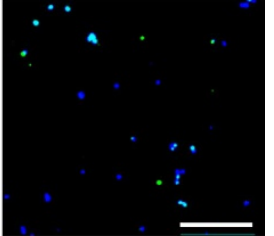

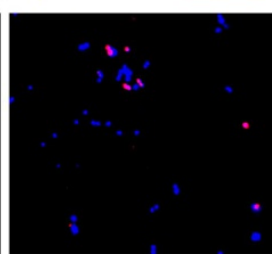

b
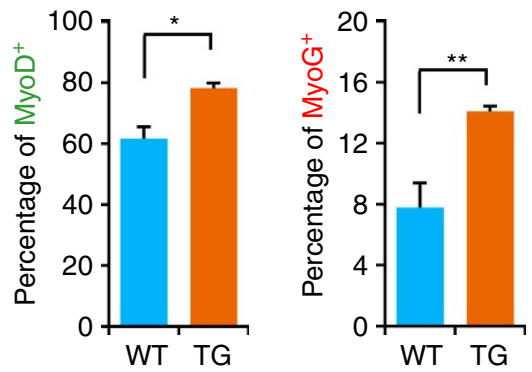

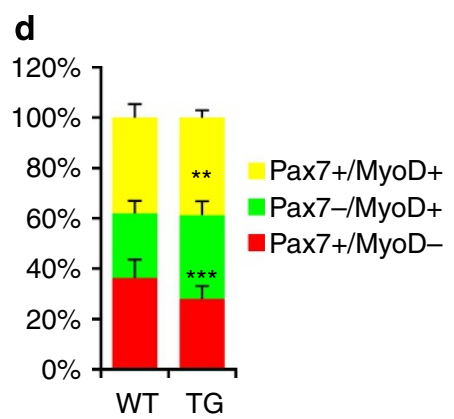

Figure 4 | Pax7 ${ }^{\text {Lo }}$ satellite cells of miR-431 TG mice are more primed for differentiation than the WT controls. (a) Satellite cells from the Pax7Cre::R26mTmG::miR-431 and Pax7Cre::R26mTmG controls were sorted using FACS, cultured for $48 \mathrm{~h}$ in growth medium and immunostained for MyoD (green) and MyoG (red). Blue, 4',6-diamidino-2-phenylindole dihydrochloride (DAPI) staining. Scale bars, $100 \mu \mathrm{m}$. (b) Numbers of the MyoD + and MyoG + cells in a. Values are means \pm s.e.m. of triplicate experiments. ${ }^{\star} P<0.05$, ${ }^{\star} P<0.01$. Two-tailed Student's $t$-test was used for all statistical testings. (c) Double staining for Pax7 and MyoD in expanded satellite cells from single fibres isolated from EDL muscle and cultured for $72 \mathrm{~h}$. The data are from five mice for each genotype and more than 200 myofibres were analysed. Scale bar, $50 \mu \mathrm{m}$. (d) Numbers of Pax $7^{+} / \mathrm{MyoD}^{+}, \mathrm{Pax} 7^{-} / \mathrm{MyoD}^{+}$ and Pax ${ }^{+} /$MyoD $^{-}$cells in cultured single fibres from miR-431 TG and WT mice in c. Values are means \pm s.e.m. ${ }^{\star \star} P<0.01,{ }^{\star \star} P<0.001$. Two-tailed Student's t-test was used for all statistical testings.

indicating that miR-431 caused activated SCs to proliferate during the proliferative phase of muscle regeneration. At 3 days, the well-defined myogenic differentiation marker MHC 3 (Myh3), also called embryonic MHC (eMHC), was highly expressed in the damaged muscle of TG mice but not of WT mice (Fig. 5i), indicating precocious differentiation in miR-431 TG mice. At 7 days after injection, Myh3 mRNA was less abundant in the damaged muscles of the TG mice than that of WT mice (Fig. 5j), showing that neonatal myofibres formed faster in TG mice than in WT controls. At 31 days after CTX injection, the number of Pax ${ }^{+}$cells (Fig. 6a,b) and the levels of Pax7 protein (Fig. 6c) and mRNA (Fig. 6d) were significantly lower in TG mice, whereas $M y o G$ mRNA levels in muscle (Fig. 6e) were much higher. Thus, miR-431 overexpression has a long-term functional effect in promoting the muscle regeneration in mice.

Since TG SCs were preferentially differentiated rather than selfrenewed, we thought that TG mice subjected to a second CTXinduced injury might have fewer quiescent SCs and an increased number of smaller myofibres than WT mice. Indeed, 5 days after the second injury, TG mice had smaller myofibres in greater abundance (Fig. 6f,g) and higher levels of $M y o G$ mRNA (Fig. 6h) in newly formed regenerated myofibres. Moreover, at 31 days, TG mice had no change in the number of $\mathrm{Pax}^{+}$SCs, but Pax7 transcripts were significantly lower than those in WT mice (Fig. 6i).

The morphological and molecular evidence supports the notion that myogenic differentiation is remarkably accelerated in miR-431 TG mice during muscle regeneration. Although we have noticed that MyoD expression in the SCs of damaged muscle (Fig. 5g) from TG mice was inconsistent with that of ex vivo cultured single fibres (Fig. 4d), it is possible that the inconsistence might be due to the different responses of SCs under the two experimental conditions. Together, our findings indicate that miR-431 may help to accelerate muscle regeneration in mice by mediating SC functions with enriched subpopulation of Pax $7^{\mathrm{Lo}}$ SCs, which are primed more for differentiation and less for selfrenewal.

The miR-431 transgene reduces muscular dystrophy in $m d x$ mice. Since miR-431 accelerated muscle regeneration in mice, we investigated the possibility that it would reduce muscular dystrophy in mice. We generated $m d x$ mice overexpressing miR-431 (miR-431::mdx; Supplementary Fig. 12) and compared their muscular morphology with that of $m d x$ mice. The two groups of mice did not differ overtly in muscle mass, muscle architecture or the number and size of myofibres (Supplementary Fig. 13).

To further characterize the dystrophic phenotype of $m i R-431:: m d x$ mice, we measured serum creatine kinase levels, an indicator of skeletal muscle damage, and examined membrane permeability of myofibres by their uptake of Evans blue dye $\mathrm{e}^{37}$. Serum creatine kinase levels were 12 -fold higher in $m d x$ mice than in WT mice (C57BL/6 mice), but were significantly lower in $m i R-431:: m d x$ than in $m d x$ mice (Fig. 7a). The Evans blue dye uptake was also significantly lower in $m i R-431:: m d x$ than in $m d x$ mice (Fig. $7 \mathrm{~b}, \mathrm{c}$ ). These morphological findings indicate that miR-431 overexpression reduces the dystrophic phenotype of $m d x$ mice.

To assess muscle function and performance in the mice, we measured running time to exhaustion in a downhill treadmill 

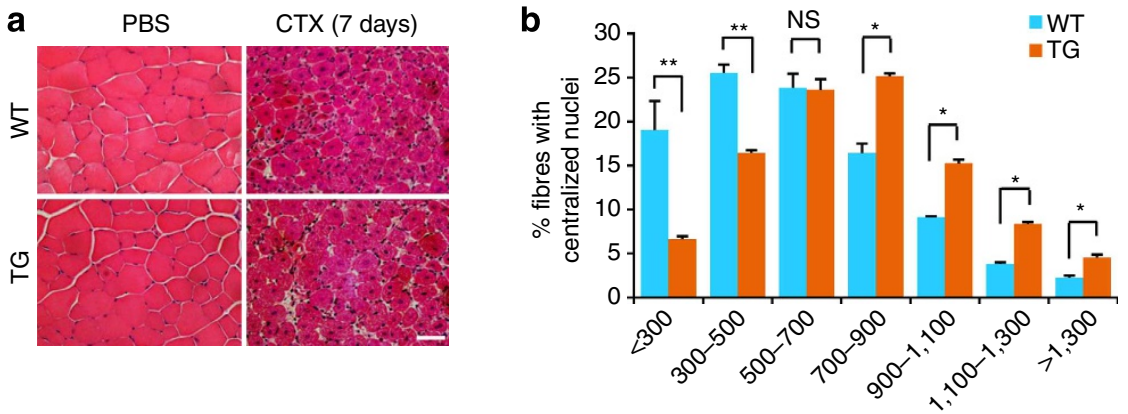
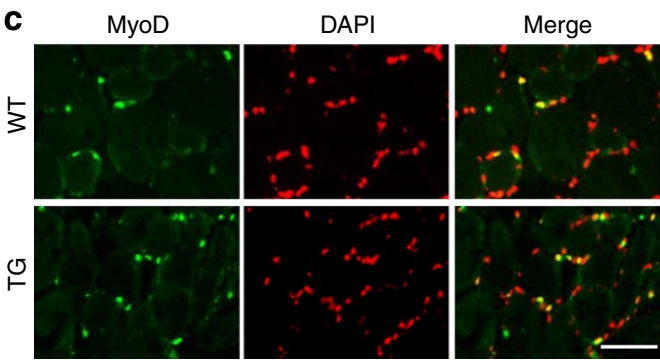

d
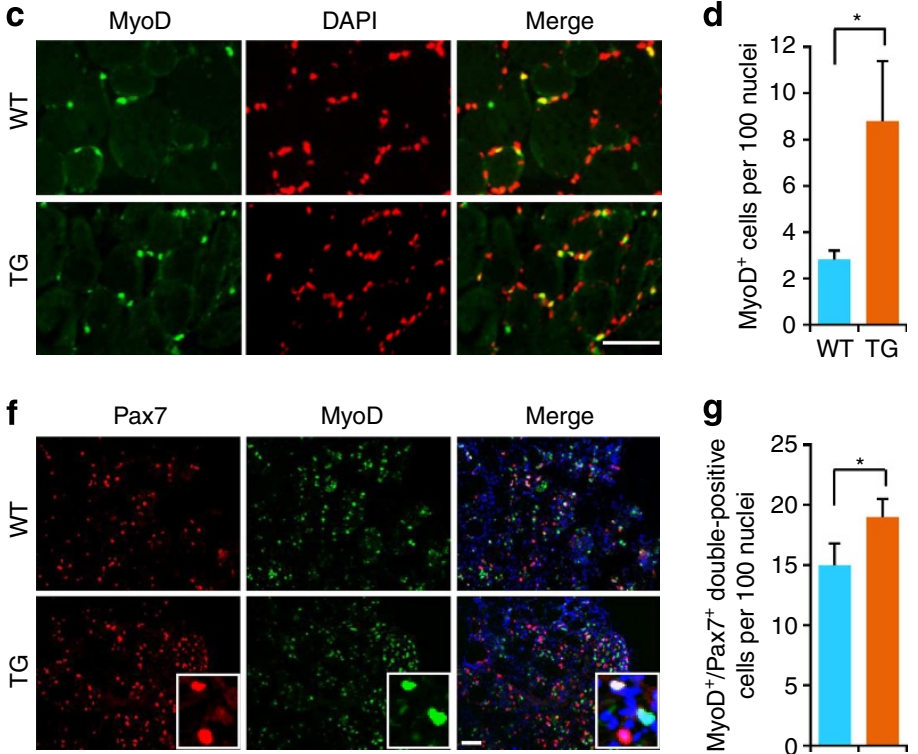

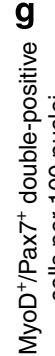

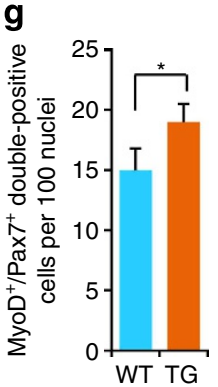

h
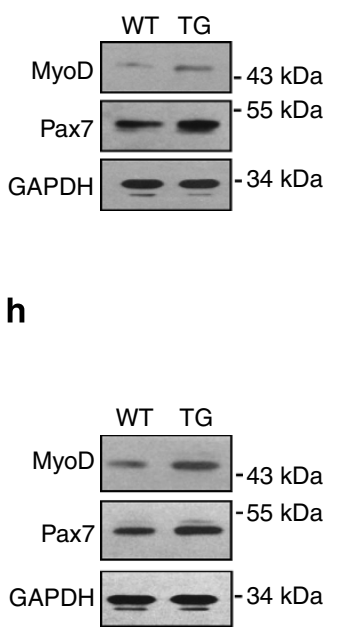
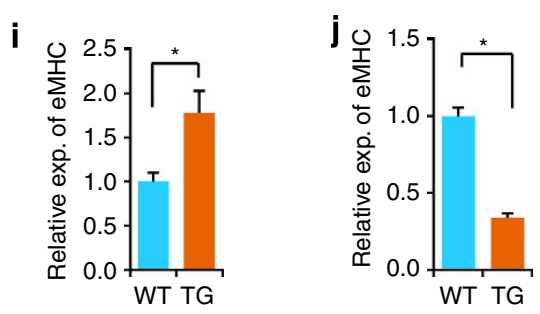

Figure 5 | miR-431 TG mice exhibit accelerated skeletal muscle regeneration. The $H$ and $O$ lines of the miR-431 TG mice had similar phenotypes. The data presented here are from the analysis of $\mathrm{H}$ line mice. Values are mean \pm s.e.m. or one representative value from five pairs of WTand TG mice. ${ }^{\star} P<0.05$, ${ }^{\star \star} P<0.01$. NS, not significant. Two-tailed Student's $t$-test was used for all statistical testings. (a) Representative haematoxylin and eosin (H\&E)-stained sections of TA muscle 7 days after injury induced by CTX injection. Controls were injected with PBS. Scale bar, $50 \mu \mathrm{m}$. (b) Cross-sectional area of regenerated myofibres with centralized nuclei, calculated from the $\mathrm{H} \& \mathrm{E}$-stained sections in a,c. A representative view of $M y o D$ staining on sections of TA muscle 1 day after CTX injury. Green, MyoD; red, DAPI. Scale bar, $50 \mu \mathrm{m}$. (d) Number of MyoD ${ }^{+}$cells in sections of TA muscle 1 day after CTX injury (shown in c). (e) Western blots showing expression levels of MyoD and Pax7 in TA muscle 1 day after CTX injury. GAPDH was the loading control. (f) Representative sections of TA muscle 3 days after CTX injury, double-stained for Pax7 (red) and MyoD (green). Scale bar, $50 \mu$ m. (g) Number of $\mathrm{Pax} 7^{+} / \mathrm{MyoD}^{+}$double-positive cells in sections of TA muscle 3 days after CTX injury (shown in $\mathbf{f}$ ). (h) Western blots showing expression of MyoD and Pax7 in TA muscle 3 days after CTX injury. GAPDH was the loading control. (i,j) Expression of eMHC in TA muscle 3 days (i) and 7 days (j) after injury, detected using RT-qPCR.

exercise paradigm. At 5 months of age, $m d x$ mice ran for a significantly shorter time than WT controls (C57BL/6 mice; Fig. 7d). However, $m i R-431:: m d x$ mice had longer running times compared with $m d x$ mice, indicating less muscle injury and less dysfunction. In addition, the peak tetanic force was 2.5 -fold greater (Fig. 7e) and the peak twitch force was 3-fold greater (Fig. 7f) in $m i R-431:: m d x$ mice.

To further confirm that miR-431 regulates SC proliferation and differentiation during the degeneration/regeneration cycle, we immunostained SCs in sections of regenerating TA muscle with antibodies against Pax7 and MyoD (Fig. 7g). Proliferating $\left(\mathrm{Pax} 7^{+} / \mathrm{MyoD}^{+}\right)$and differentiating $\left(\mathrm{Pax}^{-} / \mathrm{MyoD}^{+}\right)$cells were significantly more abundant in $m d x:: m i R-431$ muscle than in $m d x$ muscle (Fig. 7h), further corroborating the critical role of miR-431 in promoting proliferation and differentiation of activated SCs during skeletal muscle regeneration in mice.

Since the miR-431 transgene driven by the chicken $\beta$-actin promoter was also overexpressed in myofibres of the TG mice, 
a First round damage: 31 d.p.i.

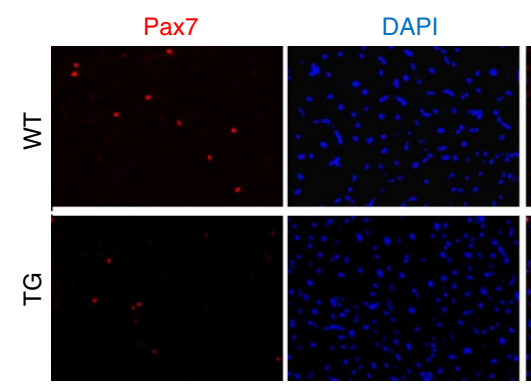

d

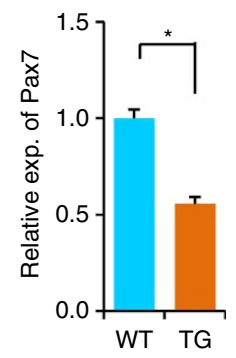

g

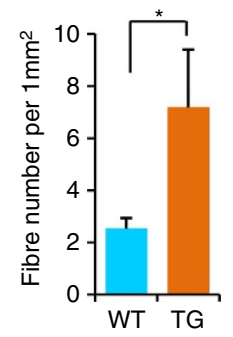

e

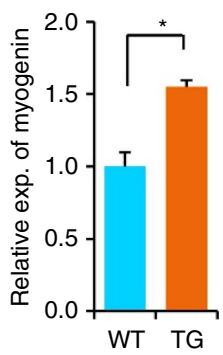

h

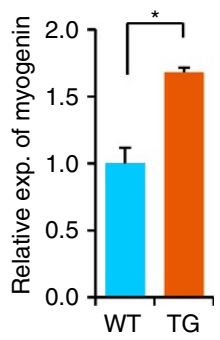

b

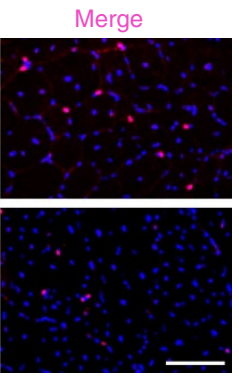

c

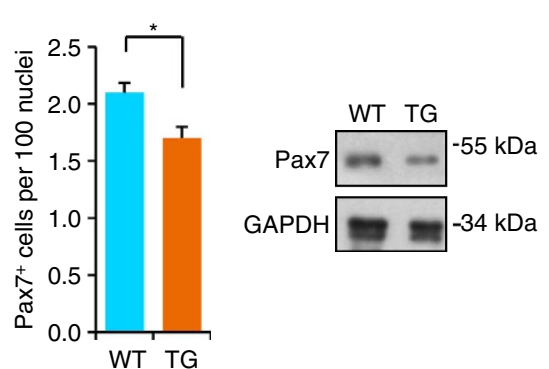

f Second round damage: 5 d.p.i.

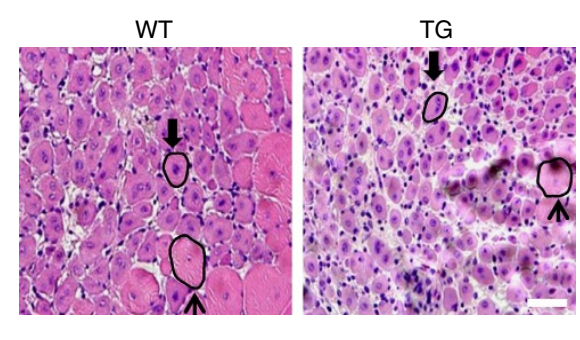

i Second round damage: 31 d.p.i.
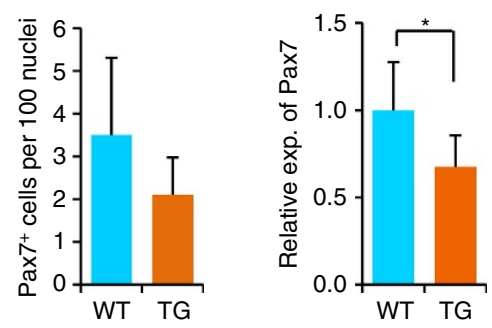

Figure 6 | miR-431 does not deplete the satellite pool after two rounds of injury. One representative value or means \pm s.e.m. from five pairs of WT and TG mice. ${ }^{\star} P<0.05$. Two-tailed Student's $t$-test was used for all statistical testings. (a) Pax7 staining on sections of CTX-damaged TA muscles from miR-431 TG and WT mice 31 days after injury (d.p.i.). Scale bar, $50 \mu \mathrm{m}$. (b) Number of Pax7-positive cells in the stained sections in a. (c) Western blots showing Pax7 expression in injured TA muscle 31 d.p.i. (d,e) Pax7 and myogenin gene expression in the samples in $\mathbf{c}$ were determined using real-time RT-PCR. GAPDH was the internal control. (f) Newly formed regenerated myofibres with centralized nuclei in H\&E-stained sections of TA muscle 5 days after the second round of CTX injury. Scale bar, $50 \mu \mathrm{m}$. (g) Numbers of regenerated myofibres in sections in $\mathbf{f}, \mathbf{h}$. MyoG gene expression in the samples in $\mathbf{f}$, analysed using real-time RT-PCR. GAPDH was the internal control. (i) Number of Pax7-positive cells in sections of TA muscle at 31 days after the second round of CTX-induced injury. Pax7 expression in the same samples was examined using real-time RT-PCR.

miR-431 might improve the dystrophic phenotype in $m d x$ mice by direct effects on myofibre structure and function. To test this possibility, we examined expression of dystrophin and utrophin (Fig. 7i,j) and gene markers of different types of myofibres (Supplementary Fig. 14a) and genes related to the metabolic features of the fibre types (Supplementary Fig. 14b) in the TA muscle. The tested genes were expressed at similar levels in $m d x:: 431$ and $m d x$ mice. Evidently, miR-431 reduces muscular dystrophy in $m d x:: m i R-431$ mice mainly through effects on SC functions. Overall, these findings are consistent with the histological and morphological data and suggest a molecular explanation of how miR-431 overexpression functionally reduces the dystrophic phenotype in $m d x$ mice.

\section{Discussion}

The functional relevance of SC heterogeneity is illustrated by the distinct myogenic and metabolic features of $\mathrm{Pax} 7^{\mathrm{Hi}}$ and $\mathrm{Pax} 7^{\mathrm{Lo}}$ $\mathrm{SCs}^{20}$. For example, Pax $7^{\mathrm{Lo}}$ cells are more committed to myogenic differentiation than the stem-like $\mathrm{Pax}^{\mathrm{Hi}}$ cells $^{20}$. It has been reported that $\mathrm{Pax} 7^{\mathrm{Hi}}$ and $\mathrm{Pax} 7^{\mathrm{Lo}}$ subpopulations are mediated at the transcriptional level ${ }^{20}$. However, how is the level of Pax7 post-transcriptionally regulated in SCs to establish these different subpopulations, and what biological effects do these subpopulations have in vivo? In this study, we showed that miR-431 is predominantly expressed in the skeletal muscle and post-transcriptionally fine-tunes the $\operatorname{Pax} 7$ level by directly targeting Pax7 in SCs. Significantly, we found that Pax $7^{\text {Lo }}$ SCs are remarkably enriched in miR-431 TG mice, indicating that miR-431 has a critical role in controlling SC heterogeneity by mediating the Pax7 level. Furthermore, we found that Pax $7^{\text {Lo }}$ cells have a greater potential for myogenic differentiation and, in miR-431 TG mice, they speed muscle regeneration by promoting SC differentiation. Finally, we found that overexpression of miR-431 in a mouse model of muscular dystrophy (miR-431::mdx mice) markedly reduces the disease phenotype.

miR-431 is from the miRNA cluster that is processed from the antisense strand of maternally expressed imprinted gene Rtl1 (ref. 38). Rtl1 is a paternally expressed intronless protein-coding gene, and six miRNAs (miR-431, miR-433, miR-127, miR-434, miR-432 and miR-136) are maternally generated when the Rtl1 gene is transcribed in the opposite direction ${ }^{39-41}$. However, until 

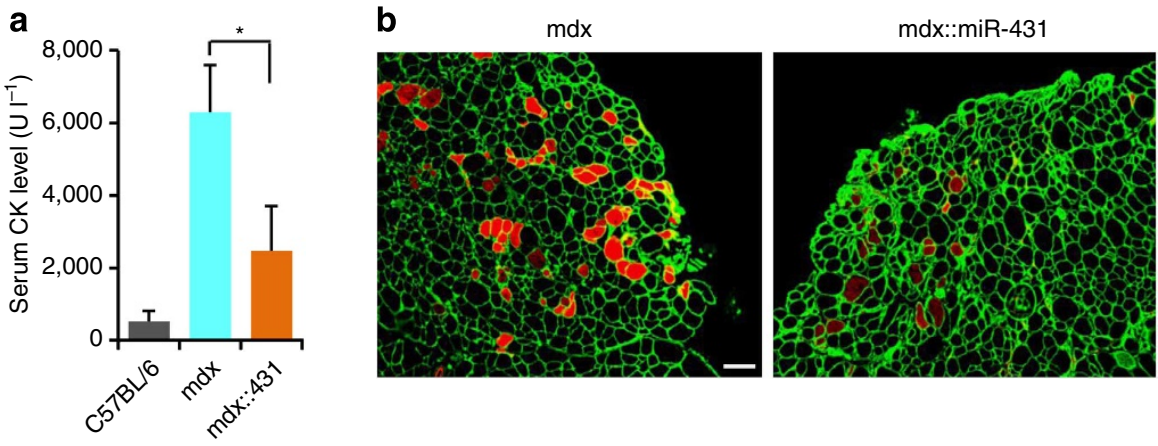

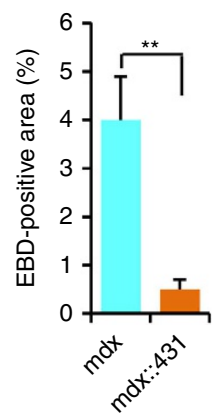

d

g

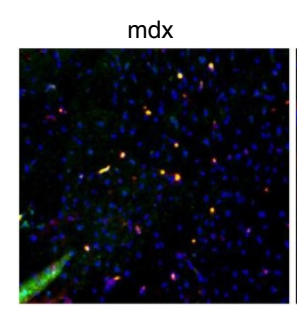

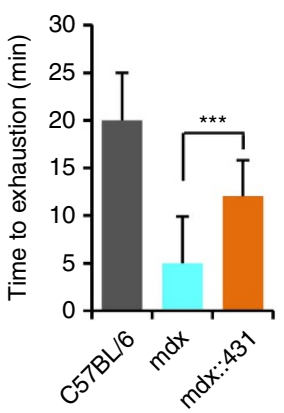

e

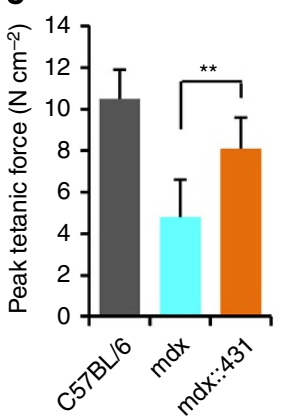

f

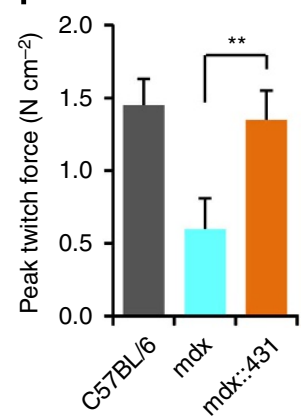

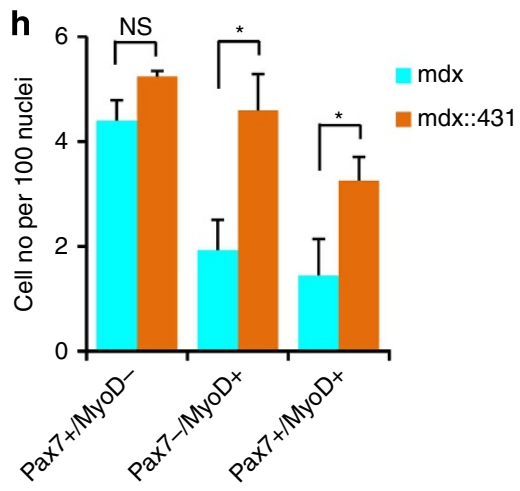
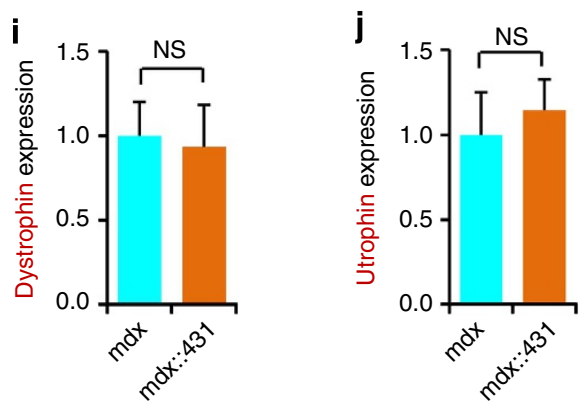

Figure 7 | The miR-431 transgene reduces the dystrophic phenotype in $\mathbf{m d x}$ mice. miR-431::mdx mice were generated by crossing miR-431 TG mice with $m d x$ mice. Values are means \pm s.e.m. of experiments with five to eight mice at 5 months of age. ${ }^{\star} P<0.05,{ }^{\star \star} P<0.01,{ }^{\star \star \star} P<0.001$. NS, not significant. (a) Serum creatine kinase (CK) levels in C57BL/6 WT and $m d x$ control or miR-437::mdx mice. (b) Evans blue dye uptake in TA muscle. Scale bar, $50 \mu \mathrm{m}$. (c) Percentage of Evans blue-positive fibre area in TA muscle of $m d x$ and $m i R-431:: m d x$ mice. (d) Running time to exhaustion on the downhill treadmill test. (e) Maximal twitch force induced by electrical stimulation in vitro to elicit tetanic contractions in EDL muscle from C57BL/6, $m d x$ and miR-437::mdx mice. (f) Peak twitch force induced in EDL muscle by electrical stimulation in vitro. (g) Pax7 (red) and MyoD (green) double staining on sections of TA muscles from mdx and mdx::miR-431 mice. Scale bar, $100 \mu \mathrm{m}$. (h) Numbers of Pax $7^{+} / \mathrm{MyoD}^{+}, \mathrm{Pax}^{-} / \mathrm{MyoD}^{+}$and Pax $7^{+} / \mathrm{MyoD}^{-}$cells in the stained sections in $\mathbf{g}$. (i,j) Expression of dystrophin (i) and utrophin (j) in TA muscle of $m d x$ and $m d x:$ :miR-431 mice, analysed using real-time RT-PCR. GAPDH was the internal control.

now, no evidence has indicated the function of these miRNAs in muscle development and regeneration. We showed that miR-431 is predominantly expressed in the skeletal muscle and regulates myogenesis in vitro and in vivo by targeting Pax7. Other studies suggested that miRNAs from the anti-Rtll strand directly target Rtl1, causing the Rtl1 transcript to be cleaved by the 
RNA-induced silencing complex ${ }^{40}$. Still other studies suggested that Rtl1 is associated with the double-muscled phenotype of Callipyge sheep (CLPG region) $)^{39}$, suggesting that this genetic locus helps to regulate muscle development and regeneration. However, we found no difference in Rtl1 expression in the skeletal muscle of miR-431 TG and WT control mice (Supplementary Fig. 15). Thus, miR-431 regulates myogenic differentiation independently of $R t l 1$.

We used several strategies to show that miR-431 TG muscle harbours more Pax $7^{\mathrm{Lo}}$ SCs, which are prone to be more primed for differentiation in response to myogenic stimuli. Pax7 expression was lower in SCs from TG mice than in those from WT controls. Moreover, the biological features of SCs from miR-431 TG mice were very similar to those reported for Pax $7^{\mathrm{Lo}}$ cells $^{27}$. First, SCs from miR-431 TG mice had fewer stemness markers (CXCR4 and CD34) and higher expression of the differentiation gene MyoG. Second, SCs from TG mice more readily underwent differentiation and less readily underwent selfrenewal. Our findings reveal a critical role for miR-431 in establishing and maintaining SC heterogeneity by fine-tuning Pax7 expression, and they provide a novel mechanism for generating mice with an enhanced population of $\mathrm{Pax}^{\mathrm{Lo}}$ SCs.

Pax7 is a key regulator of SC proliferation, self-renewal and differentiation, and its expression and transcriptional activity are tightly regulated. For example, MyoG represses Pax7 transcription by binding to regulatory sequences in the Pax7 promoter via the HMGB1-RAGE axis. Rage ${ }^{-l-}$ myoblasts have higher levels of Pax7, greater proliferation potential and lower differentiation potential than WT myoblasts, and deleting Rage promotes asymmetric division of myoblasts ${ }^{42}$. MyoD and $\mathrm{MyoG}$ downregulate Pax7 post-translationally ${ }^{43}$; however, in myoblasts committed to differentiation, post-transcriptional downregulation is mediated by miR-1, miR-206 and miR-486 (refs 30,44 ). Here we showed that miR-431 regulates SC functions in miR-431 TG mice and we provide convincing evidence that the Pax7 level is tightly controlled by miR-431 in SCs in vitro and in vivo. Furthermore, we found that miR-431 critically regulates the establishment and maintenance of the Pax $7^{\mathrm{Lo}}$ subpopulation in mice by targeting Pax7.

More intriguingly, cells in the Pax $7^{\mathrm{Lo}}$ subpopulation described in ref. 20 have a higher metabolic status, as shown by their higher ATP levels and better oxidative capacity. However, the functional relevance of this specific and unique feature of $\operatorname{Pax} 7^{\mathrm{Lo}}$ cells has not been explored yet, and fundamental questions remain to be addressed. Why and how are the metabolic features of the Pax $7^{\text {Lo }}$ subpopulation correlated to biological processes during skeletal muscle development and regeneration? What molecular mechanism underlies the metabolic state of $\mathrm{Pax}^{\mathrm{Lo}}$ cells? Our miR-431 TG mice, which harbour an enriched Pax $7^{\text {Lo }}$ subpopulation, will be a good genetic model for answering these questions about skeletal muscle development and regeneration.

Finally, we also showed that in $m d x$ mice, a model of Duchenne muscular dystrophy ${ }^{45}$, miR-431 lessens the severity of the phenotype. Although this disease is caused primarily by a mutation in the gene encoding dystrophin ${ }^{46}$, several genes slow disease progression in $m d x$ mice ${ }^{47-50}$. Thus, therapeutic strategies may not be limited to those directly targeting the dystrophin gene. Interestingly, many studies suggest that the genes controlling SC proliferation and differentiation strongly influence the pathogenesis of $m d x$ mice. For example, Wnt7a ameliorates muscular dystrophy in $m d x$ mice by stimulating SC expansion and myofibre hypertrophy via the AKT/mTOR anabolic pathway ${ }^{51}$. Moreover, miR-206 delays the progression of muscular dystrophy in $m d x$ mice by promoting SC differentiation through targeting negative regulators of myogenic differentiation, including Notch3, Pax7 and $I G F b p 5$ (ref. 52). Our finding that miR-431 markedly reduces the dystrophic phenotype in miR-431::mdx mice raises the possibility that delivering miR-431 mimics or manipulating the downstream targets of miR-431 will benefit patients with Duchenne muscular dystrophy (DMD) or other muscular diseases.

\section{Methods}

Mice and animal care. All animal procedures were approved by the Animal Ethics Committee of Peking Union Medical College, Beijing, China. Mice were housed in the animal facility and had free access to water and standard rodent chow. miR-431 TG mice were generated by the Model Animal Research Center of the Nanjing University. Rosa26-mTmG mice were a gift from Dr Shihuan Kuang (Purdue University). $M d x$ mice were from the Model Animal Research Center of the Nanjing University. Pax7-Cre mice were provided by Dr Zhenguo Wu (The Hong Kong University of Science and Technology). C57BL/6 mice were purchased from the Vital River Laboratories Company in Beijing.

Cell sorting. SCs were FACS-sorted from different mouse lines, including miR-431 TG and WT mice and Pax7-Cre::Rosa26-mTmG::miR-431 TG and Pax7-Cre::Rosa26$m T m G$ male reporter mice at 4 weeks. Mononucleated muscle-derived cells were isolated from hindlimb muscles using dispase and collagenase digestion. The cells from the two reporter cell lines were directly sorted with a BD Aria II Cell Sorting System. Mononuclear cells from non-reporter mice were blocked with goat serum for $10 \mathrm{~min}$ and were incubated with antibodies against CD45, CD31, Scal and VCAM in DMEM with $2 \%$ fetal bovine serum (FBS) for $15 \mathrm{~min}$ at $4{ }^{\circ} \mathrm{C}$. Antibodies used to sort SCs include FITC-CD45 (553080, 1:100 dilution), FITC-CD31 (553372, 1:100 dilution), PE-Scal (553108, 1:100 dilution), biotin-VCAM (553331, 1:100 dilution) and streptavidin-APC (554067, 1:100 dilution; all from BD Pharmingen). Immunostained cells were briefly washed, passed through a $40-\mu \mathrm{m}$ nylon mesh (Falcon) and suspended at a concentration of $10^{3}-10^{7}$ cells per ml. Cells were further separated with the BD Aria II. Sorting gates were strictly defined on the basis of control cells stained with single antibodies as well as the patterns of forward scatter and side scatter of SCs in preliminary tests.

Muscle injury and regeneration. Muscle regeneration was induced by injections of CTX (Sigma). Male mice at 8 weeks were anaesthetized by intraperitoneal injection of ketamine $\left(10 \mathrm{mg} \mathrm{kg}^{-1}\right)$ and xylazine $\left(1 \mathrm{mg} \mathrm{kg}^{-1}\right)$ For monitoring muscle regeneration, muscle injury was induced in 8-week-old mice by injecting CTX (50 $\mu \mathrm{l}$ of $10 \mu \mathrm{M}$ CTX in PBS) into the midbelly of the right TA muscle. As an internal control, the left TA muscle of each mouse was injected with PBS $(50 \mu \mathrm{l})$. Muscles were harvested at 1,3,5 and 7 days after injection to assess the completion of regeneration and repair.

Cell culture. $\mathrm{C} 2 \mathrm{C} 12$ cells were cultured in the growth medium consisting of DMEM (Gibco) supplemented with $4.5 \mathrm{gl}^{-1}$ glucose, $10 \% \mathrm{FBS}, 1 \%$ antibiotic/ antimycotic and $1 \%$ gentamycin at $37^{\circ} \mathrm{C}$ in a $5 \% \mathrm{CO}_{2}$ atmosphere. At $50-60 \%$ confluence, cells were switched to differentiation medium (DMEM with 2\% horse serum). C2C12 cell lines stably overexpressing miR-431 were established by infection with lentivirus containing H1-miR-431-CMV-Puromycin (Genechem). Pax7 overexpression plasmids were a gift from Dr Denis C. Guttridge (The Ohio State University).

Isolating and staining single myofibres. Single myofibres were isolated from the EDL muscles of 8-week-old male mice by digestion with collagenase I (C-0130, Sigma). The muscle was incubated in $3 \mathrm{ml}$ of $0.2 \%$ collagenase I in serum-free DMEM in a shaking water bath at $37^{\circ} \mathrm{C}$ for $45-60$ min. Digestion was considered complete when the muscle looked less defined and slightly swollen, with hair-like single fibres flowing away from the edges. The digested muscles were placed in a Petri dish, and myofibres were isolated under a microscope. Single fibres were placed in six-well plates pre-coated with horse serum. Then, $2 \mathrm{ml}$ of fibre medium (DMEM supplemented with $20 \%$ FBS, $0.5 \%$ chick embryo extract and penicillinstreptomycin) was added. The fibres were cultured for $72 \mathrm{~h}$ at $37^{\circ} \mathrm{C}$ in a $5 \% \mathrm{CO}_{2}$ atmosphere, fixed with $4 \%$ paraformaldehyde and stained for Pax7 and MyoD. For statistical analyses, $\mathrm{Pax}^{+}$and $\mathrm{MyoD}^{-}$cells were counted in at least 40 single fibres per mouse in five pairs of TG and WT mice.

Isolating primary myoblasts. Primary myoblasts were isolated from the hindlimb skeletal muscle of male mice at 4 weeks, minced and digested in a mixture of type I collagenase and Dispase B (Roche Applied Science). Cells were filtered from debris, centrifuged and cultured in growth medium (F-10 Ham's medium supplemented with $20 \% \mathrm{FBS}, 4 \mathrm{ng} \mathrm{ml}^{-1}$ basic fibroblast growth factor and $1 \%$ penicillin-

streptomycin) on collagen-coated cell culture plates at $37^{\circ} \mathrm{C}$ in $5 \% \mathrm{CO}_{2}$ (ref. 53). 
Northern blot analysis. Total RNA was extracted from the heart, liver, brain lung, kidney, intestine, spleen and skeletal muscle of 3-week-old male mice, separated using PAGE ( $7 \mathrm{M}$ urea) on $15 \%$ gels, and transferred to a nylon membrane ( + ; Amersham). T4 DNA kinase (Fermentas) was used to label miR-431 probes with $\gamma-{ }^{32}$ p-ATP. RNA blots were hybridized in ULTRAhyb (Ambion) at $42{ }^{\circ} \mathrm{C}$ overnight, washed twice ( 5 min each) with $2 \times$ SSC/ $0.1 \%$ SDS wash buffer at $42^{\circ} \mathrm{C}$, followed by stringent washes $(2 \times 30 \mathrm{~min})$ with $0.1 \times \mathrm{SSC} / 0.1 \% \mathrm{SDS}$ wash buffer at $42{ }^{\circ} \mathrm{C}$. RNA blots were then exposed to X-ray film at $-80^{\circ} \mathrm{C}$. Full scans of northern blots were presented in Supplementary Fig. 16.

Western blot analysis. Muscle tissues and $\mathrm{C} 2 \mathrm{C} 12$ cells were lysed in a buffer containing $50 \mathrm{mM}$ Tris $\mathrm{pH} 7.5,150 \mathrm{mM} \mathrm{NaCl}, 0.5 \%$ Nonidet P40 and protease and phosphatase inhibitors. The protein lysates were resolved using SDS-PAGE, transferred to a polyvinylidene fluoride membrane and immunoblotted with primary antibodies against MHC (MF20, 1:500), MyoG (F5D, 1:500) and Pax7 (from DSHB, 1:500); MyoD (BD Biosciences, 1:250); and GAPDH (Glyceraldehyde 3-phosphate dehydrogenase; Millipore, 1:10,000). Membranes were washed for $30 \mathrm{~min}$, incubated with horseradish peroxidase-conjugated secondary antibodies (Zhongshanjinqiao Corporation) for $1 \mathrm{~h}$ at room temperature and washed for 30 min. Each membrane was then placed into Detection Solution (Thermo), incubated for $1 \mathrm{~min}$ at room temperature and exposed to X-ray film. Full scans of all western blots are available in Supplementary Fig. 17.

Immunohistochemistry. $\mathrm{C} 2 \mathrm{C} 12$ cells were seeded in 12 -well plates $\left(1 \times 10^{4}\right.$ cells per $\mathrm{cm}^{2}$ per well) in the growth medium; at $50-60 \%$ confluence, the cells were transferred to the differentiation medium for 24 or $36 \mathrm{~h}$, fixed with $4 \%$ formaldehyde for $5 \mathrm{~min}$ and permeabilized in $0.1 \%$ Triton X-100 in PBS for $15 \mathrm{~min}$ at room temperature. Cells were blocked with $3 \%$ bovine serum albumin for $30 \mathrm{~min}$ and then incubated with primary antibodies (F5D, 1:200; MF20, 1:300) for $1 \mathrm{~h}$. Fluorescein-conjugated anti-mouse secondary antibodies (Zhongshanjinqiao Corporation; $1: 200$ ) were added in $0.1 \%$ Triton X-100 plus $3 \%$ bovine serum albumin in PBS for $1 \mathrm{~h}$ at $37^{\circ} \mathrm{C} .4^{\prime}, 6$-diamidino-2-phenylindole dihydrochloride was then added for $2 \mathrm{~min}$ at room temperature. After several washes with PBS, cells were examined using fluorescence microscopy.

RT-PCR and real-time RT-PCR analyses. Total RNA from cells was extracted with Trizol reagent (Invitrogen). Expression of mature miRNAs was determined with the miRNA-specific TaqMan microRNA assay kit (Applied Biosystems) and the ABI IQ5 Sequence Detection System (Applied Biosystems). U6 was used for normalization. mRNA expression was analysed with Fast EvaGreenqPCR Master Mix (Applied Biosystems) and normalized to GAPDH. All primers used for RT-PCR were included in Supplementary Table 1.

Transfection and luciferase assays. For construction of the $3^{\prime}$-UTR-luciferase reporter, the multiple cloning site of the pGL-3-Control vector (Promega) was removed and placed downstream of the luciferase gene. The $3^{\prime}$-UTRs of mouse Pax7 were amplified using PCR and were cloned into the pGL-3-Control vector resulting in Pax7-3'-UTR constructs. HEK 293 cells were co-transfected with Pax7$3^{\prime}$-UTR and miR-431 mimics. Empty pGL-3 vector was a negative control. w-UTR is a Pax7-3'-UTR with miR-431-binding site inserted downstream of the luciferase gene in the pGL- 3 control vector. mlutr and m2utr are mutant forms of the Pax7 $3^{\prime}$-UTR. A Renilla luciferase plasmid was co-transfected with a firefly luciferase construct as a transfection control. The results are expressed as firefly luciferase activity relative to Renilla luciferase activity.

Treadmill. The treadmill test was performed using the Exer3/6 (Columbus Instruments). Mice were acclimated to treadmill running four times (every other day) before the test. Mice ran on the treadmill at $20^{\circ}$ downhill, starting at a speed of $16 \mathrm{~cm} \mathrm{~s}^{-1}$. After $3 \mathrm{~min}$, the speed was increased by $2 \mathrm{~cm} \mathrm{~s}^{-1}$ to a final speed of $36 \mathrm{~cm} \mathrm{~s}^{-1}$. Exhaustion was defined as the inability of the mouse to remain on the treadmill, despite electrical prodding.

Force measurements. EDL muscles were constantly immersed in physiological saline solution containing $118.5 \mathrm{mM} \mathrm{NaCl}, 4.7 \mathrm{mM} \mathrm{KCl}, 2.4 \mathrm{mM} \mathrm{CaCl}_{2}, 3.1 \mathrm{mM}$ $\mathrm{MgCl}_{2}, 25 \mathrm{mM} \mathrm{NaHCO} 3,2 \mathrm{mM} \mathrm{NaH}{ }_{2} \mathrm{PO}_{4}$ and $5.5 \mathrm{mM}$ D-glucose. All solutions were continuously bubbled with $95 \% \mathrm{O}_{2} / 5 \% \mathrm{CO}_{2}$ (vol/vol) and maintained at $\mathrm{pH}$ 7.4. All experiments were carried out at $25^{\circ} \mathrm{C}$. Contractions were elicited by passing a current between two platinum electrodes placed on opposite sides of the muscle. Twitch contractions were elicited with a single 0.3-ms square pulse of $10 \mathrm{~V}$ (supramaximal voltage); tetanic contractions were elicited with a 200 -ms train of the same pulse at $200 \mathrm{~Hz}$. Contractions were elicited every $2 \mathrm{~min}$ during the experiment. Muscle length was adjusted to obtain maximum tetanic force, and a 30-min equilibrium period was allowed before force-frequency measurements. Force was measured with a dual-mode muscle lever system (Grass X88 Stimulator) and digitized at $5 \mathrm{kHz}$ with a analogue-digital board (Grass). Peak twitch force and peak tetanic force were calculated as the difference between the maximum force during contraction and the force measured at $5 \mathrm{~ms}$ before the contraction.

Statistical analysis. Values are presented as means \pm s.e.m. The statistical significance of the difference between two the means was calculated with the $t$-test. $P<0.05$ was considered statistically significant.

\section{References}

1. Relaix, F. et al. Pax3 and Pax7 have distinct and overlapping functions in adult muscle progenitor cells. J. Cell Biol. 172, 91-102 (2006).

2. Lepper, C., Partridge, T. A. \& Fan, C. M. An absolute requirement for Pax7-positive satellite cells in acute injury-induced skeletal muscle regeneration. Development 138, 3639-3646 (2011).

3. Sambasivan, R. et al. Pax7-expressing satellite cells are indispensable for adult skeletal muscle regeneration. Development 138, 3647-3656 (2011).

4. Oustanina, S., Hause, G. \& Braun, T. Pax7 directs postnatal renewal and propagation of myogenic satellite cells but not their specification. EMBO J. 23 , 3430-3439 (2004).

5. McKinnell, I. W., Parise, G. \& Rudnicki, M. A. Muscle stem cells and regenerative myogenesis. Curr. Topics Dev. Biol. 71, 113-130 (2005).

6. Kuang, S., Kuroda, K., Le Grand, F. \& Rudnicki, M. A. Asymmetric self-renewa and commitment of satellite stem cells in muscle. Cell 129, 999-1010 (2007).

7. Collins, C. A. et al. Stem cell function, self-renewal, and behavioral heterogeneity of cells from the adult muscle satellite cell niche. Cell 122, 289-301 (2005).

8. Charge, S. B. \& Rudnicki, M. A. Cellular and molecular regulation of muscle regeneration. Physiol. Rev. 84, 209-2383 (2004)

9. Buckingham, M. Myogenic progenitor cells and skeletal myogenesis in vertebrates. Curr. Opin. Genet. Dev. 16, 525-532 (2006).

10. Seale, P. et al. $\operatorname{Pax} 7$ is required for the specification of myogenic satellite cells. Cell 102, 777-786 (2000).

11. Lepper, C., Conway, S. J. \& Fan, C. M. Adult satellite cells and embryonic muscle progenitors have distinct genetic requirements. Nature 460, 627-631 (2009).

12. Tapscott, S. J. The circuitry of a master switch: Myod and the regulation of skeletal muscle gene transcription. Development 132, 2685-2695 (2005).

13. Bajard, L. et al. A novel genetic hierarchy functions during hypaxial myogenesis: Pax3 directly activates Myf5 in muscle progenitor cells in the limb. Genes Dev. 20, 2450-2464 (2006)

14. McKinnell, I. W. et al. Pax7 activates myogenic genes by recruitment of a histone methyltransferase complex. Nat. Cell Biol. 10, 77-84 (2008).

15. Kuang, S., Charge, S. B., Seale, P., Huh, M. \& Rudnicki, M. A. Distinct roles for Pax7 and Pax3 in adult regenerative myogenesis. J. Cell Biol. 172, 103-113 (2006).

16. Relaix, F., Rocancourt, D., Mansouri, A. \& Buckingham, M. A Pax3/Pax7dependent population of skeletal muscle progenitor cells. Nature 435, 948-953 (2005).

17. von Maltzahn, J., Jones, A. E., Parks, R. J. \& Rudnicki, M. A. Pax7 is critical for the normal function of satellite cells in adult skeletal muscle. Proc. Natl Acad. Sci. USA 110, 16474-16479 (2013).

18. Schultz, E. Satellite cell proliferative compartments in growing skeletal muscles. Dev. Biol. 175, 84-94 (1996).

19. Beauchamp, J. R. et al. Expression of CD34 and Myf5 defines the majority of quiescent adult skeletal muscle satellite cells. J. Cell Biol. 151, 1221-1234 (2000).

20. Rocheteau, P., Gayraud-Morel, B., Siegl-Cachedenier, I., Blasco, M. A. \& Tajbakhsh, S. A subpopulation of adult skeletal muscle stem cells retains all template DNA strands after cell division. Cell 148, 112-125 (2012).

21. Olguin, H. C. \& Olwin, B. B. Pax-7 up-regulation inhibits myogenesis and cell cycle progression in satellite cells: a potential mechanism for self-renewal. Dev. Biol. 275, 375-388 (2004).

22. Zhao, Y. et al. Dysregulation of cardiogenesis, cardiac conduction, and cell cycle in mice lacking miRNA-1-2. Cell 129, 303-317 (2007).

23. Liu, N. et al. microRNA-133a regulates cardiomyocyte proliferation and suppresses smooth muscle gene expression in the heart. Genes Dev. 22, 3242-3254 (2008).

24. Wang, H. et al. NF-kappaB-YY1-miR-29 regulatory circuitry in skeletal myogenesis and rhabdomyosarcoma. Cancer Cell 14, 369-381 (2008).

25. Taulli, R. et al. The muscle-specific microRNA miR-206 blocks human rhabdomyosarcoma growth in xenotransplanted mice by promoting myogenic differentiation. J. Clin. Invest. 119, 2366-2378 (2009).

26. Yan, D. et al. MicroRNA-1/206 targets c-Met and inhibits rhabdomyosarcoma development. J. Biol. Chem. 284, 29596-29604 (2009).

27. Cheung, T. H. et al. Maintenance of muscle stem-cell quiescence by microRNA-489. Nature 482, 524-528 (2012).

28. O'Rourke, J. R. et al. Essential role for Dicer during skeletal muscle development. Dev. Biol. 311, 359-368 (2007).

29. Chen, J. F. et al. The role of microRNA-1 and microRNA-133 in skeletal muscle proliferation and differentiation. Nat. Genet. 38, 228-233 (2006). 
30. Chen, J. F. et al. microRNA-1 and microRNA-206 regulate skeletal muscle satellite cell proliferation and differentiation by repressing Pax7. J. Cell Biol. 190, 867-879 (2010).

31. Crist, C. G. et al. Muscle stem cell behavior is modified by microRNA-27 regulation of Pax3 expression. Proc. Natl Acad. Sci. USA 106, 13383-13387 (2009).

32. Cacchiarelli, D. et al. MicroRNAs involved in molecular circuitries relevant for the Duchenne muscular dystrophy pathogenesis are controlled by the dystrophin/nNOS pathway. Cell Metab. 12, 341-351 (2010).

33. Alexander, M. S. et al. Regulation of DMD pathology by an ankyrin-encoded miRNA. Skel. Muscle 1, 27 (2011).

34. van Rooij, E. et al. Control of stress-dependent cardiac growth and gene expression by a microRNA. Science 316, 575-579 (2007).

35. Creuzet, S., Lescaudron, L., Li, Z. \& Fontaine-Perus, J. MyoD, myogenin, and desmin-nls-lacZ transgene emphasize the distinct patterns of satellite cell activation in growth and regeneration. Exp. Cell Res. 243, 241-253 (1998).

36. Zammit, P. S. All muscle satellite cells are equal, but are some more equal than others? J. Cell Sci. 121, 2975-2982 (2008).

37. Hamer, P. W., McGeachie, J. M., Davies, M. J. \& Grounds, M. D. Evans Blue Dye as an in vivo marker of myofibre damage: optimising parameters for detecting initial myofibre membrane permeability. J. Anat. 200, 69-79 (2002).

38. Sekita, Y. et al. Role of retrotransposon-derived imprinted gene, Rtl1, in the feto-maternal interface of mouse placenta. Nat. Genet. 40, 243-248 (2008).

39. Byrne, K. et al. The imprinted retrotransposon-like gene PEG11 (RTL1) is expressed as a full-length protein in skeletal muscle from Callipyge sheep. PLoS ONE 5, e8638 (2010).

40. Davis, E. et al. RNAi-mediated allelic trans-interaction at the imprinted Rtl1/Peg11 locus. Curr. Biol. 15, 743-749 (2005).

41. Hagan, J. P., O’Neill, B. L., Stewart, C. L., Kozlov, S. V. \& Croce, C. M. At least ten genes define the imprinted Dlk1-Dio3 cluster on mouse chromosome 12qF1. PLoS ONE 4, e4352 (2009).

42. Riuzzi, F., Sorci, G., Sagheddu, R. \& Donato, R. HMGB1-RAGE regulates muscle satellite cell homeostasis through p38-MAPK- and myogenindependent repression of Pax7 transcription. J. Cell Sci. 125, 1440-1454 (2012).

43. Olguin, H. C., Yang, Z., Tapscott, S. J. \& Olwin, B. B. Reciprocal inhibition between Pax7 and muscle regulatory factors modulates myogenic cell fate determination. J. Cell Biol. 177, 769-779 (2007).

44. Dey, B. K., Gagan, J. \& Dutta, A. miR-206 and -486 induce myoblast differentiation by downregulating Pax7. Mol. Cell Biol. 31, 203-214 (2011).

45. Grady, R. M. et al. Skeletal and cardiac myopathies in mice lacking utrophin and dystrophin: a model for Duchenne muscular dystrophy. Cell 90, 729-738 (1997).

46. Hoffman, E. P., Brown, R. H., Jr. \& Kunkel, L. M. Dystrophin: the protein product of the Duchenne muscular dystrophy locus. Cell 51, 919-928 (1987).

47. Minetti, G. C. et al. Functional and morphological recovery of dystrophic muscles in mice treated with deacetylase inhibitors. Nat. Med. 12, 1147-1150 (2006).
48. Li, H., Mittal, A., Makonchuk, D. Y., Bhatnagar, S. \& Kumar, A. Matrix metalloproteinase-9 inhibition ameliorates pathogenesis and improves skeletal muscle regeneration in muscular dystrophy. Hum. Mol. Genet. 18, 2584-2598 (2009).

49. Kumar, A. \& Bhatnagar, S. Matrix metalloproteinase inhibitor batimastat alleviates pathology and improves skeletal muscle function in dystrophindeficient mdx mice. Am. J. Pathol. 177, 248-260 (2010).

50. Acharyya, S. et al. Interplay of IKK/NF-kappaB signaling in macrophages and myofibers promotes muscle degeneration in Duchenne muscular dystrophy. J. Clin. Invest. 117, 889-901 (2007).

51. von Maltzahn, J., Renaud, J. M., Parise, G. \& Rudnicki, M. A. Wnt7a treatment ameliorates muscular dystrophy. Proc. Natl Acad. Sci. USA 109, 20614-20619 (2012).

52. Liu, N. et al. microRNA-206 promotes skeletal muscle regeneration and delays progression of Duchenne muscular dystrophy in mice. J. Clin. Invest. 122, 2054-2065 (2012).

53. Cifelli, C. et al. KATP channel deficiency in mouse flexor digitorum brevis causes fibre damage and impairs $\mathrm{Ca} 2+$ release and force development during fatigue in vitro. J. Physiol. 582, 843-857 (2007).

\section{Acknowledgements}

We thank Dr Denis C. Guttridge for the gift of the Pax7 overexpression plasmids, Dr Shihuan Kuang for providing the Rosa26-mTmG mice and Dr Zhenguo Wu for the gift of Pax7-Cre mice. This work was supported by grants from the National Basic Research Program of China (2011CBA01104, 2011CB965002 and 2014CB964703) and the National Natural Science Foundation of China (31030041, 31271470 and 91019010).

\section{Author contributions}

R.W. and H.L. contributed equally to this work and carried out most of the experiments L.Z. performed muscle damage and regeneration analysis; X.Z. and J.M. helped in the experiment for the muscle regeneration; R.Z. and C.L. provided extra technical assistance; H.W. helped in manuscript preparation; Y.Z. and D.Z. conceived the study and wrote the manuscript. All authors participated in the interpretation of the data and production of the final manuscript.

\section{Additional information}

Supplementary Information accompanies this paper at http://www.nature.com/ naturecommunications

Competing financial interests: The authors declare no competing financial interests.

Reprints and permission information is available online at http://npg.nature.com/ reprintsandpermissions/

How to cite this article: $\mathrm{Wu}, \mathrm{R}$. et al. MicroRNA-431 accelerates muscle regeneration and ameliorates muscular dystrophy by targeting Pax7 in mice. Nat. Commun. 6:7713 doi: $10.1038 /$ ncomms8713 (2015). 